\title{
Metanarratives and Storytelling in Contemporary Mainstream Popular Music: Romeo and Juliet in the Making of the Star Persona
}

\section{ABSTRACT}

This article analyzes how mainstream artists respond to the dynamics of online fan communities, developing complex metanarratives that interrelate their songs and music videos with their "personal" activity on social media. Audiences analyze in depth and discuss each release, contributing to its viralization on the internet. However, these strategies need strong narratives that allow convincing developments and transmedia storytelling, and this is where literature becomes a significant source of inspiration. I argue that the assumption (or subversion) of popular literary characters and narratives contributes to a positioning of artists in the music scene and facilitates their "reading" by the audience. To illustrate this process, I analyze the references to Romeo and Juliet by mainstream pop artists in the last decade, paying special attention to Troye Sivan's debut album Blue Neighborhood (2015), considered a homosexual version of Shakespeare's drama, and to Halsey's concept album Hopeless Fountain Kingdom (2017), understood as a queer version of the play. Both artists explained their personal reading of Shakespeare's drama as a way of expressing their own feelings and experiences. These examples of metanarrative storytelling achieved their aim, and millions of fans engaged with both artists, discussing lyrics, photos and music videos related to Romeo and Juliet on social media.

Keywords: transmedia storytelling, Romeo and Juliet, music. 


\section{INTRODUCTION}

Popular music is one of the main cultural contents on the internet: music videos top the charts of YouTube, music streaming platforms increase the number of subscribers each year, and videogames and social media develop new strategies to offer live performances (see Marshmello concert in "Fortnite" or Coachella Festival on YouTube). But the remediation of popular music to the internet is not only a question of offering new ways of accessing music, it rather implies the development of new strategies to appeal to internet users and to adapt music to the new dynamics of consumption. Considering the data, we can confirm that the music industry succeeded in its adaptation to the new context. In the last decade things have changed significantly; social media and audiovisual content have become central for artists, and releases are constantly beating records, especially with regard to their impact in a short period of time. ${ }^{1}$ This situation cannot be explained merely by referring to the increase of internet users or to the current ubiquity of online consumption. It needs a far-reaching approach that delves into the strategies that have been implemented, and a certain perspective that will allow us to evaluate what changes there have been and how certain practices have become standardized and habitual in the promotion of artists.

Firstly, audiovisual streaming technologies have restored the interest of the popular music industry in audiovisual formats. Undoubtedly, the popularity of YouTube played an important role, but we should not forget the increasing attention paid to audiovisual content by music streaming services (Spotify video, Apple music) and the audiovisual technologies in social media that rapidly normalized practices like Instagram stories, Facebook live videos, and popularized apps like Snapchat and TikTok, especially among young users. In this context, music videos gained relevance in the industry and demonstrated its versatility to deploy a new aesthetic that has been analyzed in depth by Carol Vernallis (Unruly Media). On the internet, music video has become more flexible and likely to gather influences from various media, developing intertextual strategies that have worked specially well for the online audience. In fact, many official videos have triggered prosumer practices that have contributed to the promotion of artists and have challenged the formal boundaries of this audiovisual genre.

At the same time, artists improved their skills in social media, engaging their fan communities and achieving great impact with their online activity. These communication technologies might have once been seen as an easy

1 Most-viewed video in 24 hours (beaten several times in 2018 and 2019). 
tool to spread information, but they have revealed themselves to be more about interaction than one-way communication. Certainly, the management of artists' social media profiles has changed over the last decade, they have intensified their presence and their exposure responding to the immediacy of these forms of communication. This is a challenging situation for artists, who need to regularly feed their social media profiles, showing closeness but keeping the aura of stardom and dealing with "the dialectical tension between intimacy and distance, attraction and rejection" (Risi 153).

Fan communities demand constant activity, regular interaction and, ultimately, content. This is where transmedia storytelling and metanarratives become necessary for artists. Not long ago, artists' media exposure used to be restricted to promotional campaigns for the release of an album, and their communication with the audience was established through broadcasting media (TV, radio, magazines); everything was pretty much under control, and their public appearances had a clear motive and a discursive strategy that they just needed to follow. Nowadays, the importance of being constantly present on social media has driven new strategies and rhetorical tools for communication: single releases happen every few months, and promotion campaigns are not reduced to publicize the releasing date through a countdown; they have been extended in time and have become more complex, intensifying their presence on social media and especially using all sorts of intertwined audiovisual formats (teaser, lyric video, behind the scenes, etc.). Thus, master narratives are more important than ever to interconnect the wide range of actions and contents that participate in a promotional campaign nowadays.

\section{THE BENEFITS OF METANARRATIVES AND TRANSMEDIA STORYTELLING}

Communication and cultural production on the internet have been widely analyzed from the perspective of transmedia storytelling, mainly following the works of Henry Jenkins. These approaches served to highlight the affordances of digital technologies and the development of participatory culture. However, the aim here is to bring transmedia storytelling to the terrain of narratology in order to explore how artists appropriate and rework existing narratives to articulate discourses and to position their star persona. Of course, this is not a new trend from the (post)digital age: artists have always found ways to establish connections with all kinds of stories. However, I argue that the current communication arena facilitates these strategies and allows more complex promotional campaigns that aim to erase the distance between the person and the star persona, especially 
due to the intensification of their exposure in social media. Thus, nowadays, artists are constantly rewriting their narratives in a process in which "the self forms a trajectory of development from the past to the anticipated future" (Giddens 75), and the elements that articulate their identities are distributed in different media and interact in a constant flux. The control of time for artists is now more important than ever to create a successful narrative; we are not referring here to the actions carefully scheduled in any promotion, but rather to the way this narrative re-signifies the past from the present of the artist and projects his/her future (Ricœur 345).

We all use social media as a virtual projection of ourselves; making decisions on those aspects we share of our lives, we also decide when to publish and how to present what we are posting. Thus, we create a narrative of ourselves that also plays in a flexible way with time; even if this process can be tracked in the timeline of our social media profiles, we constantly recall people, actions and events from the past reinterpreted in our present. We have normalized these techniques to narrate our lives through texts, videos and photos in which we share our experiences and thoughts, our likes and dislikes on different topics. We do this from what Bakhtin calls a dialogic consciousness: we become writers of our auto/biography, and those that are skilled and know how to use these narrative tools to engage with other users succeed and gain more followers.

These practices may be better understood as metanarratives, especially in the case of artists dealing with their star persona. Lyotard's post-modern conception of this term is particularly useful to approach how artists articulate the discourse of their public persona as a hyperreal subject through songs, videos and (social) media communication. All these texts interact and participate in the configuration of a master narrative for artists that does not need to be true but plausible, even if it is always suspected of being fake and entering the terrain of simulacrum (in Baudrillard terms). The intertextual scheme of media interactions needs to keep the logic of a credible and appealing narrative that appears to be real to the fan community.

Again, these practices are not new, but they have been intensified and extensively deployed in the post-digital age through transmedia storytelling strategies in films, series, music, videogames, literature. All these media are being analyzed from the perspective of post-classical narratology that expanded beyond structuralism to embrace a wide range of transdisciplinary approaches (Alber and Fludernik 5). Thus, Thanouli explores post-classical narration in $21^{\text {st }}$ century film and television, and Vernallis (Embracing the Media Swirl) identifies a "media swirl" in the digital age. In popular music, I argue that post-classical narrative is especially noticeable in transmedia metanarratives that intertwine music videos and social media communication. Metanarratives have always been 
relevant for music videos; Simon Frith highlighted the role of videos in the "creation of the star" and Andrew Goodwin used the term to explain how artists use videos to articulate messages and engage with their audiences. But, as Mathias Korsgaard argues, "music video today is in itself a central component of the field of new digital media" (164).

Nowadays, the music video is a pivotal element in the marketing plan of any release: it is a medium with great impact on the release of a single, it is announced on social media with stills, teasers and trailers, and it structures the promotional life of the songs on an album. Besides, music videos have become more intertextual in the (post)digital age, they often articulate the artists' master narrative in different ways: they gather together artists' "personal" information and opinions on different matters expressed not only in the song, but also in interviews, performances, public appearances and (especially) on social media; they establish connections between the singles of an album, and between different periods of the artist's career, referring to actions, topics and characters performed by the artist in previous albums and music videos. Thus, I argue that metanarratives in music videos may be both synchronic with the content that is published in other media and diachronic, revisiting and updating the artist's past from the present.

In the last decade, we find many examples of music videos that articulate synchronic and diachronic metanarratives in which artists try to erase the boundaries between the person and the persona. In fact, visual albums perfectly illustrate this strategy, and they appear as a new category of music video in the 2010s (see Justin Bieber's Purpose or Beyoncé's Lemonade). But many other music videos use similar tactics, like including "Easter eggs" to challenge fan communities and generate discussions on the possible hidden messages in a video (see Ariana Grande's "Breathing" or Taylor Swift's "Me!"). Particularly interesting in this regard are cases like Britney Spears's "Hold It Against Me," where we see excerpts from previous music videos played in the background on TV screens, and Taylor Swift's “Look What You Made Me Do," where several characters performed by this artist in previous videos interact. At the end of this video we see all of them arguing while the "talking" Swift takes the floor significantly saying: "I would very much like to be excluded from this narrative."

Metanarratives are not only techniques that configure formal patterns in music videos. They are powerful strategies to articulate ideological discourses that deal with ethics, or rather with meta-ethics because they express political subject-positions, morality and cultural values. In this regard, "meta-narratives both supply the structure for individual narratives and the criteria for perception and appreciation by which sense is made of that structure. This is why ideas about the social world can seem selfevident" (Stephens and McCallum 6). Thus, music videos may be read 
as palimpsests, as cultural artefacts of their time, and the metanarratives they put into play might be understood in the same way that literature regularly updates classic narratives, such as Pygmalion or Faust, from a contemporary perspective.

The possibilities of metanarratives in the current mediascape have favoured the emergence of concept albums in contemporary mainstream pop. This is a format historically linked to rock (from Pink Floyd to Radiohead), but since the 2010s mainstream pop artists have perceived the benefits of developing a concept to interconnect the wide range of media that articulate a musical release. Some notable recent examples are Janelle Monáe's Dirty Computer (2018) and Madonna's Madame X (2019). This might also be understood as a response to the proliferation of $360^{\circ}$ deals in music industry during the 2000s; nowadays artists obtain revenues from many different sources, and marketing campaigns work better under the umbrella of metanarratives capable of sustaining transmedia strategies. The new reality of music marketing implies a diversification of roles that the artists need to play in their career; mainstream artists are now more versatile and need skills as communicators, posers, entertainers, etc.

Being inscribed in a strong narrative might be very helpful to create the star persona of an artist. However, it is not only about impersonating characters or playing roles in music videos; it is rather a question of the perspective adopted to approach that narrative and the subject positioning of the artist in the whole story. The narrative must be recognizable and appealing to the fan community, but it should also provide something new and related to contemporary social and political issues and values. As Lyndon C. S. Way argues, "by vaguely articulating discourses of being anti-establishment, musicians articulate authenticity for themselves and their fans" (114). Thus, it is very common that artists rework traditional narratives including their position on current concerns like global warming, LGBT rights and gender equality, i.e. topics that may connect them to their fan community and generate debate. This is especially relevant in a media context where broadcasting media are losing audiences and celebrities' posts on social media constantly activate countless debates.

\section{QUEERING ROMEO AND JULIET IN CONTEMPORARY POPULAR MUSIC}

I will illustrate the use of metanarratives in contemporary popular music by analyzing the adaptations of Romeo and Juliet. Shakespeare chose for his drama an archetypal narrative rooted in classic literature and popular in the Italian Renaissance. The drama approaches the dialectics of love and 
hate, and presents a dramatic structure that drives the story of the main characters from love to death and their families from hate to reconciliation. This narrative facilitates reflections on several universals, like the catharsis of death and the challenge to established social norms (in this case, the fight for a forbidden love) that can easily be updated to the social context of different periods. In fact, Shakespeare's drama was adapted since its early representations, removing comic characters (Mercutio, Nurse) and introducing iconic scenic resources that are not in the text (the balcony).

The drama has been adapted to romance, cinema, opera, musicals, etc. following Shakespeare's work, but adjusting the text, the cast or the aesthetics to appeal to diverse audiences at different times. And the story has inspired celebrated adaptations like the musical (and film) West Side Story, introducing the issues of migration and youth violence in New York during the mid-twentieth century. Małgorzata Pawłowska argues that "in the twentieth century a gradual transition occurred of the linearly perceived narrative from classical to popular music" (292). This happened not only in musicals, but especially in songs that narrate the story of the two lovers from different perspectives: The Supremes, Tom Waits, Lou Reed, Dire Straits, Bruce Springsteen and Radiohead recorded songs inspired by the drama.

Romeo and Juliet is probably the most popular drama in the Western World nowadays. Students read and study this text in high schools, and it has become a paradigm of romantic love in popular culture. Moreover, to challenge established social norms (as it is the case with forbidden love) is a recurrent theme for every young generation and it has been the main topic of successful productions (Grease, Titanic). Recently, Romeo and Juliet has been reworked in many ways to express female empowerment and LGBTQ relationships: that is, to challenge patriarchy and heteronormativity. For instance, the traditionally sexist Pirelli calendar changed its strategy in 2020 to portray empowered women in a project entitled "Looking for Juliet," while Troian Bellisario directed the film Still a Rose (2015), an LGBTQ version of the drama. Lately, feminism and LGBTQ rights have made it to the public agenda and have become a trending topic in modern cultural productions. Women's march on Washington and \#MeToo movement (both in 2017) are two relevant examples of a new social sensibility to feminism and LGBTQ rights. GLAAD's report (2017) demonstrates that young people are more accepting of LGBTQ people than ever before in the USA.

Thus, the social terrain was ready for artists to empower female roles in the play and to queer the love story with gender bending characters. In fact, this was nothing new in opera versions of the drama; Pawłowska mentions that "in Zingarelli's opera, Romeo's role was initially written for a castrato, but in the 1820 s it was sang by prima donnas. In Vaccai's and Bellini's works, the role was written for a female performer from the 
beginning" (97). However, recent queer and feminist versions of the drama in popular music have proved to be striking and successful as metanarratives. Not long ago, homosexuality was taboo for mainstream pop artists and might have ruined their careers (see George Michael). Homosexuality and queerness are nowadays more explicit, less allusive or metaphoric. In 2008 Katy Perry released the single "I Kissed a Girl," and it triggered scandalized reactions that would seem naïve nowadays. At the same time, some skeptical voices in the LGBTQ community accused Perry of queertrivializing marketing and considered the music video male-gaze oriented. These are the risks for artists when approaching controversial topics, and Rita Ora experienced it with the reactions to her song "Girls" (2018). LGBTQ communities are very active online, and recognized homosexual and queer artists are celebrated and heavily followed, as demonstrated the success of the hashtag \#20GayTeen that lesbian artist Hayley Kiyoko used on Twitter to wish a happy new year in 2018. They share music and engage with artists that show their commitment to LGBTQ rights, but they are always attentive to all their activities and ready to denounce anything suspected of being fake.

I will now focus in detail on some of the latest adaptations of Romeo and Juliet in mainstream popular music. I begin with Taylor Swift's song "Love Story" (2008) to illustrate how promotion campaigns have changed in the last decade. This was the first single from Swift's second album, Fearless, a record which signified a crossover from country to mainstream pop. The single was released in September 2008, and it was advertised on iTunes with the successful campaign "Countdown to Fearless." No specific actions were deployed on social media, and the official music video was not uploaded to her YouTube channel until 16 June 2009. Swift states in several interviews that she wrote the song based on an autobiographical love story that was not approved of by her parents, and the similarities with Romeo and Juliet made her relate it to Shakespeare's drama. She tells the story from the perspective of Juliet and reworks the final part to include a happy ending. Both the song and the music video escape any controversies and follow all the patterns of a heterosexual romantic love story. There are no political intentions in her appropriation of the drama, no critical distance, and Swift's approach to the story appears to be anecdotical, treating it as the paradigm of true love. This is not surprising as it perfectly fits the metanarrative of the artist at the time.

In 2015 Troye Sivan launched his first album, Wild, an EP promoted by a music video trilogy entitled Blue Neighborhood that recalls the story of Romeo and Juliet. By then, Sivan already had a successful career as a youtuber: he used to upload his own songs, covers and other videos commenting on different subjects, and he even used this platform to 
announce his homosexuality in August 2013. Of course, he used social media to promote the album release in September with an intense campaign during the summer that included meet\&greet events and several teasers. Other content was regularly published both on his official website and on his social media. Each single release meant the premiere of the music video in YouTube, and his fan community engaged with the episodic story that was narrated in the trilogy, looking for clues and speculating on the possible developments. In the first video, "Wild," we see two boys that enjoy their friendship. Both the lyrics and the video are concerned with a gradual arousal of desires that go beyond mere friendship. We also see the conflict between their families. In "Fools" both kids are teenagers, they get caught kissing by one of the fathers, who is furious and disapproves of the relationship. The rest of the song is about the necessity of escaping from the "blue neighborhood" in order to be free and enjoy their love. In the last video, "Talk Me Down," the protagonists are in their late teens; the angry father has died, and both friends meet at the funeral. Love tension is in the air, but one of the guys has opted to negate his feelings and fit social expectations by pretending to be heterosexual, which drives the story to an open ending in which his friend apparently jumps from a cliff.

Again, we see some of the dramatic patterns of Shakespeare's play: the dialectics of love and hate, the controversies between the two families, the forbidden love, the imposition of social values that repress desire and love, etc. Of course, this was easily read by the fan community as a homosexual version of Romeo and Juliet. Sivan stated the story was based on an autobiographical experience he lived growing up on the outskirts of Perth (his "blue neighborhood"), and in YouTube comments there are many questions about what aspect of Sivan's life inspired it, and what the ongoing storylines mean. This story perfectly fits Sivan's trajectory as a youtuber with a strong gay community; adopting this metanarrative gives his music a defined gay setting, something that is especially important in an incipient musical career.

The relation to Romeo and Juliet is explicit in Halsey's second LP, Hopeless Fountain Kingdom (2017). This is a concept album that took advantage of the many marketing strategies of transmedia storytelling for its promotion. The sequence is difficult to resume here, everything is based on a story that takes place in Anorev (i.e. Verona spelled backwards) and is protagonized by lesbian female character Luna Aurum ("Luna" meaning moon) and male character Solis Angelus ("Solis" meaning sun), respectively from the House of Aurum and the House of Angelus. Besides habitual promotional tools (teasers, album trailer, meet\&greet events, etc.), several innovative actions were taken. Both characters and both houses had their Twitter accounts months before the album was released. 
Several letters with Romeo and Juliet verses were sent to certain fans (and they shared them on their social media), the album cover was revealed through some kind of gymkhana where fans had to find distinct USBs hidden in different cities and share the information online to build up the cover. Halsey also started her career on social media (mainly Tumblr), so these strategies were familiar to her.

It is significant that most of the references to Romeo and Juliet are in a series of music videos that interconnect the narrative of the songs. Five music videos premiered along almost one year kept the attention (and generated speculations) of her fan community. There are many recognizable references to Shakespeare's drama: in the video of "Now or Never" the two households are presented, we see the first encounter between the main characters, and Luna (playing the role of Romeo and embodied by Halsey) visits the fortuneteller. "Strangers" shows a boxing combat between Luna and Rosa (played by bisexual singer Lauren Jauregui) that echoes the fight between Romeo and Mercutio. In "Bad at Love" Luna is hiding and escapes with some friends, whereas in the "Angelus cut" version we also see Solis sending Luna a letter. The last video, "Sorry," is a one-shot solo performance of Luna where she apologizes for breaking Solis's heart and explains her inability to engage in a relationship. Again, the end of the story is reworked, here to position Luna (Romeo) as a free spirit.

Dualistic symbology permeates both lyrics and videos. It is not only love and hate, but also life and death (in the many battles), Luna and Solis representing day and night and the celestial bodies that never get together (except in eclipses). Halsey highlights the role of honey, which appears in "The Prologue" (where she uses words from Shakespeare's prologue): she recites "Hands so bloody tastes [sic] like honey," while in "Good Mourning" it's her younger brother who recites "there's a place where love conquers all. A city where the streets fill with milk and honey." Honey means both death (blood) and hope for a better living; the same ambivalence that Shakespeare gives in the play to plants that can both heal and poison. Significantly, Halsey tweeted about bees before the album release, the letters sent to fans were stamped with a bee, and there are several bee allusions in her videos. Of course, the bees were also used in the album merchandising.

Halsey sustains the inspiration of Romeo and Juliet for the album comes from her experience of a difficult relationship break up that recalled the impossible love story between the characters. Thus, she adapted the story to make it fit with her own identity (self-defined as biracial, bipolar and bisexual) and reworked the ending to vindicate personal freedom. She was aesthetically inspired by Baz Luhrmann's film Romeo + Juliet (1997); in an online conversation between Halsey and the Australian director he 
emphasized that "the intersections about you experiencing that film and your personal life, and bringing those things together is what then makes it resonate." In fact, it is not only that Halsey adapts Shakespeare's drama to elaborate her own metanarrative, but that she does so by recalling one of the most popular postmodern versions of the play twenty years after its release.

\section{CONCLUSIONS}

A story may be told in many ways and using different kinds of communication tools and strategies. Thus, most of the popular narratives of literature evolve over time, adapting their nature to distinct media and adopting new social and political values according to the times. Popular music has always played an important part in this process, and new developments in marketing strategies and transmedia storytelling have offered artists new ways of reworking these narratives to engage fan communities in social media and to establish a closer communication with them. As demonstrated, embodying a character or adapting a narrative allows artists to create intertwined connections between their "personal" life and their star persona, all in the context of storytelling that is normally based in personal experiences. Posts, photos, music videos and other audiovisual media are increasingly more related to create complex networks that aim to "trap" audiences. We have explored the great development of these tactics when approaching Taylor Swift's promotion for her second album in 2008. Her campaign objective was iTunes sales and she delayed the free access to her music (videos) on YouTube for several months. The business was in hardcopy and digital sales at a time when social media were still at a developing stage, and this complicated transmedia strategies. A few years later, Troye Sivan and Halsey (both raised with social media) released their albums focusing on YouTube and other social media.

Metanarratives are easier to articulate for artists through different social media. In fact, if metanarratives are consistent enough, they are perfect to solve and take advantage of the constant feeding that these media request. On the other hand, these metanarratives introduce variations in the structure and the archetypes of the story in a way similar to other "media" did decades ago. Analyzing Romeo and Juliet as a case study, it was noticed that Shakespeare's drama has undergone significant changes in representations and adaptations since its early stage performances. Moreover, intertextuality between adaptations is not rare (see Halsey's and Luhrmann's versions). 
We may wonder, why Romeo and Juliet and no other Shakespeare dramas? What makes this story so successful in contemporary mainstream popular music? Beyond its popularity, I argue that the plot is especially appealing for a teenage audience, not only because of the love story, but especially for the incomprehension of society and the opposition of the lovers to parental norms. Moreover, the adaptations offer a wide range of possibilities to drive the story to a happy ending (Swift), to allude to a potential suicide (Sivan) and to stand up for freedom (Halsey). This keeps the suspense (and the speculations) in the fan community through a series of music videos that articulate the whole narrative. Besides, the story is so well-known that it is easy to relocate it in different contexts, both in time and place. Thus, Swift turns the story to the topics of medieval times (castle, clothing, dance), Sivan situates it in the present shooting the videos in the outskirts of Sydney, and Halsey places her story in a timeless apocalyptic scenario in the streets of Mexico city-significantly, the same place where Luhrmann shot most of his movie Romeo + Juliet.

If a narrative is reworked, adapted or adopted, it is because it prevails in popular culture, and it probably does so due to its versatility to introduce the issues and concerns of contemporary societies. This means the narrative is alive, not fossilized, and so it evolves. This is the case for Romeo and Juliet, which has lately experienced several feminist and LGBTQ versions, including those by Sivan and Halsey, and which is now in the process of being adapted as a hip-hop musical. Some might say that this is the fate of the classics in modern times, but we rather consider it a necessary path that any narrative must go through to become a classic.

\section{Works Cited}

Alber, Jan, and Monika Fludernik, eds. Postclassical Narratology: Approaches and Analyses. Athens, OH: Ohio State UP, 2010. Print.

Bakhtin, Mikhail. The Dialogic Imagination: Four Essays. Austin: U of Texas P, 1981. Print.

Baudrillard, Jean. Simulacra and Simulacrum. Ann Arbor: The U of Michigan P, 1994. Print.

Frith, Simon. Music for Pleasure. New York: Routledge, 1988. Print.

Giddens, Anthony. Modernity and Self-Identity: Self and Society in the Late Modern Age. Cambridge: Polity, 1991. Print.

Goodwin, Andrew. Dancing in the Distraction Factory: Music Television and Popular Culture. New York: Routledge, 1992. Print.

Jenkins, Henry. Convergence Culture: Where Old and New Media Collide. New York: New York UP, 2006. Print. 
Korsgaard, Mathias. Music Video After MTV: Audiovisual Studies, New Media, and Popular Music. New York: Routledge, 2017. Print. https:// doi.org/10.4324/9781315617565

Luhrmann, Baz, and Halsey. "Religion and hopeless fountain kingdom." Interview by Zane Lowe. Online video clip. YouTube.com. YouTube 4 May 2017. Web. 3 Aug. 2019.

Lyotard, Jean-François. The Postmodern Condition. A Report on Knowledge. Minneapolis: U of Minnesota P, 1984. Print.

Pawłowska, Małgorzata. Exploring Musical Narratology: The Romeo and Juliet Myth in Music. Hillsdale: Pendragon, 2018. Print.

Ricœur, Paul. Time and Narrative. Chicago: U of Chicago P, 1984. Print.

Risi, Clemens. "Diva Poses by Anna Netrebko: On the Perception of the Extraordinary in the Twenty-First Century." Technology and the Diva. Sopranos, Opera, and Media from Romanticism to the Digital Age. Ed. Karen Henson. London: Cambridge UP, 2016. 150-58. Print. https:// doi.org/10.1017/CBO9781139031240.011

Stephens, John, and Robyn McCallum. Retelling Stories, Framing Culture: Traditional Story and Metanarratives in Children's Literature. London: Routledge, 1998. Print.

Thanouli, Eleftheria. "Post-Classical Narration." New Review of Film and Television Studies 4.3 (2006): 183-96. Print. https://doi. org/10.1080/17400300600981900

Vernallis, Carol. Embracing the Media Swirl: Politics, Audiovisuality and Aesthetics. Los Angeles. U of California P, 2020. Print.

Vernallis, Carol. Unruly Media: YouTube, Music Video, and the New Digital Cinema. New York: Oxford UP, 2013. Print. https://doi.org/10.1093/ acprof:oso/9780199766994.001.0001

Way, Lyndon C. S. "Authenticity and Subversion: Articulations in Protest Music Videos' Struggle with Countercultural Politics and Authenticity." Music as Multimodal Discourse: Semiotics, Power and Protest. Ed. Lyndon C. S. Way and Simon McKerrel. London: Bloomsbury, 2017. 96-115. Print. https://doi.org/10.5040/9781474264419.ch-005

\section{Eduardo Viñuela is Associate Professor in the Department} of Musicology at the University of Oviedo (Spain). He has published the book El videoclip en España (2009), and has edited several books on popular music and audiovisual media. Viñuela was Visiting Researcher at the universities of Liverpool (2007), Oxford (2014) and República de Uruguay (2015), and Fulbright visiting scholar at Stanford University (2019). He also was Teaching Assistant in the Department of Media Studies at the University of Alicante (2008-10). He has chaired the Spanish branch of 
the International Association for the Study of Popular Music (IASPM) from 2009 to 2014 and was Vice-President of SIBE, the Spanish Society of Ethnomusicology (2014-18).

ORCID: 0000-0001-5732-6712

vinuelaeduardo@uniovi.es 